\title{
Fire pennexsker med lak og et penalhus i metal fra 1800-tallets Iran
}

\author{
affhv. forskningsbibliotekar Bent Lerbak Pedersen, \\ Orientalsk Samling, Det Kgl. Bibliotek
}

$\mathrm{O}$ rientalsk Samling på Det Kgl. Bibliotek har en Museumssamling bestående af eksempler på forskellige typer af tryk, håndskrifter, forskellige skrive- og trykkeriredskaber og genstande, der belyser de forskelige skriftkulturer i Mellemøsten og Asien. Objekterne i Museumssamlingen er udvalgt for at kunne anvendes i udstillingssammenhænge, foredragsvirksomhed eller som illustrationer i trykt eller elektronisk formidlingsudgivelser. De fleste af skriveog trykredskaberne er digitaliserede og kan ses online på denne adresse:

<www.kb.dk/da/nb/samling/os/

Museumssamlingen.html>

I den mellemøstlige del af samlingen er der fire penneæsker af papmaché og et penalhus i messing fra 1800 -tallet i Iran. De er alle sammen fyldt med dekorationer: pennexskerne har malede illustrationer dækket af klar lak, mens metalpenalhuset er udsmykket med geometriske mønstre og arabiske skrifttegn, hvor en del af mønstre er forsølvede eller forgyldte. Tre af pennexskerne blev erhvervet i december 1975 af fagreferent i Mellemøsten Herta Kirketerp-Møller (1908-1989) på en auktion hos Sotheby's. Den fjerde pennexske og metalpenalhuset blev anskaffet i den første halvdel af 1980'erne.

Pennexsker og penalhuse kendes fra tidlig tid i Mellemøsten og enkelte kan dateres til det 6. årh. De har i tidernes løb været fremstillet i mange slags materialer, hvor de typiske er træ, metal, ben, elfenben, læder, porcelæn og papmaché. Allerede i 500-tallet fik en penneæske er særlig symbolsk betydning $\mathrm{i}$ administrationen af et land. Når en person skulle have en topplacering i administrationen blev der ved en reception lagt en pennexske foran den person, der skulle forfremmes. Ligeledes hvis en person skulle degraderes eller afskediges blev en fremlagt penneæske foran personen fjernet (se Khalili part 2, s. 10-12)

En penneæske skulle kunne rumme redskaber forbundet med skrive processen: en lille tuschbeholder, pen, penneknive, slibesten, et stykke fladt horn til støtte for pennen, når den skulle hvæsses, en lille ske til at spæde tuschen og en papirsaks. Tidlige penalhuse, i det mindste fra det 12. århundrede, fremstillet i metal havde en integreret tuschbeholder i huset anbragt i den ene ende. Senere fik nogle penalhuse dog i stedet påloddet en tuschbeholder udvendigt på selve pennehuset tæt på åbningen. Denne beholder var forsynet med et låg. I den ene ende af pennehuset var der anbragt et låg til at holde det øvrige indhold indenfor. I Iran ses denne type af metalpanelhus fra den tidlige del af Safavid perioden (1502-1722). På grund af tuschbeholderens størrelse og placering kunne huset stikkes ned bag et bælte om livet på en person. Derfor blevet 


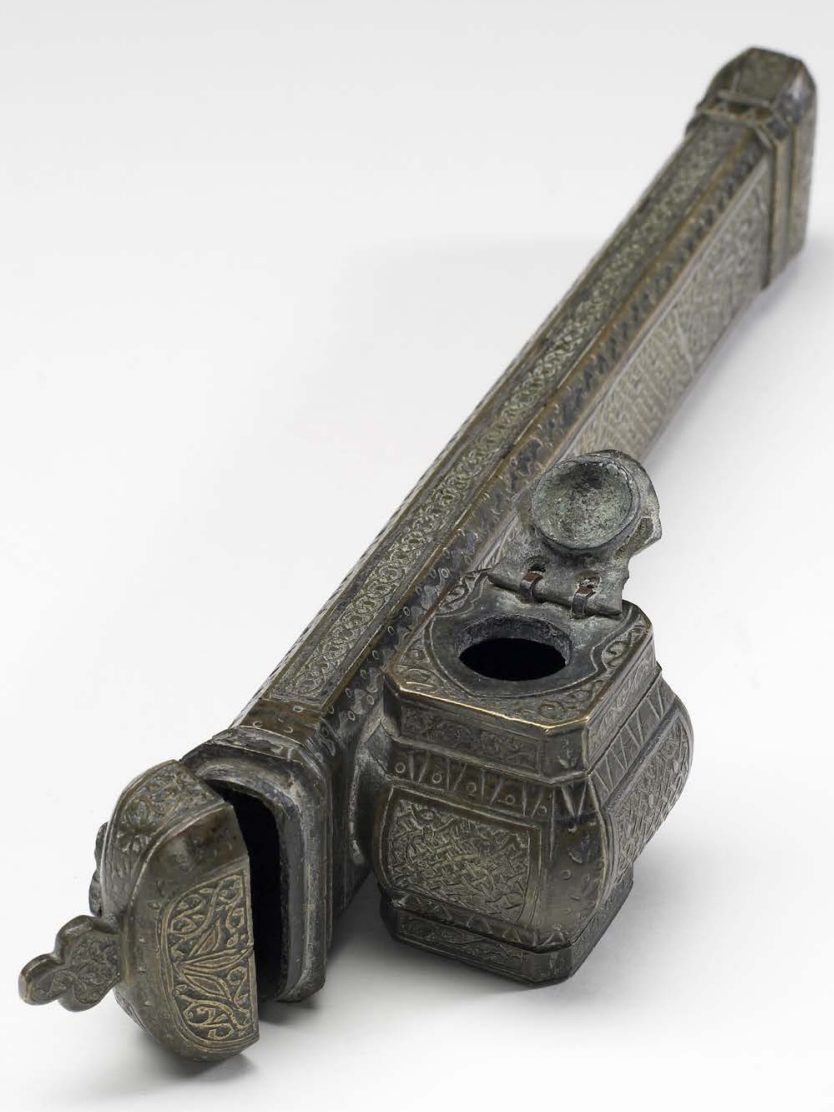

Ill. 1: Penalhus i metal, MS OS 3.

denne type af penalhuse ofte kaldt "et rejsepenalhus." Nogle penalhuse af metal havde deres hus opbygget af rør lagt over hinanden mens andre bestod af en flad aflang firkantet kasse (se Folsach s. 331). De fleste af penalhusene i metal med en ydre tuschbeholder stammer fra Iran eller det Osmanniske rige (ca. 1299-1922).

Orientalsk Samlings penalhus i metal er netop af typen med et påloddet tuschholder på en flad aflang kasse, der måler i længden $25 \mathrm{~cm}$., i højden $3,4 \mathrm{~cm}$ og bredden $2 \mathrm{~cm}$. Tuschbeholderen er ca. $4,4 \times 4,4 \mathrm{~cm}$. med en højde på $4.1 \mathrm{~cm}$. Låget på tuschbeholderen er formet som en muslingeskal. Penalhuset er fremstilet i messing og huset er reliefdekoreret i sølv og guld på alle flader inklusiv tuschbeholderen. Der er bladmønstre, geometriske mønstre og pseudoarabisk skrift på siderne af huset, mens tuschbeholderen kun har geometriske mønstre, hvor mønstret på bunden minder om stiliseret arabiske skrift (se ill. 1). 


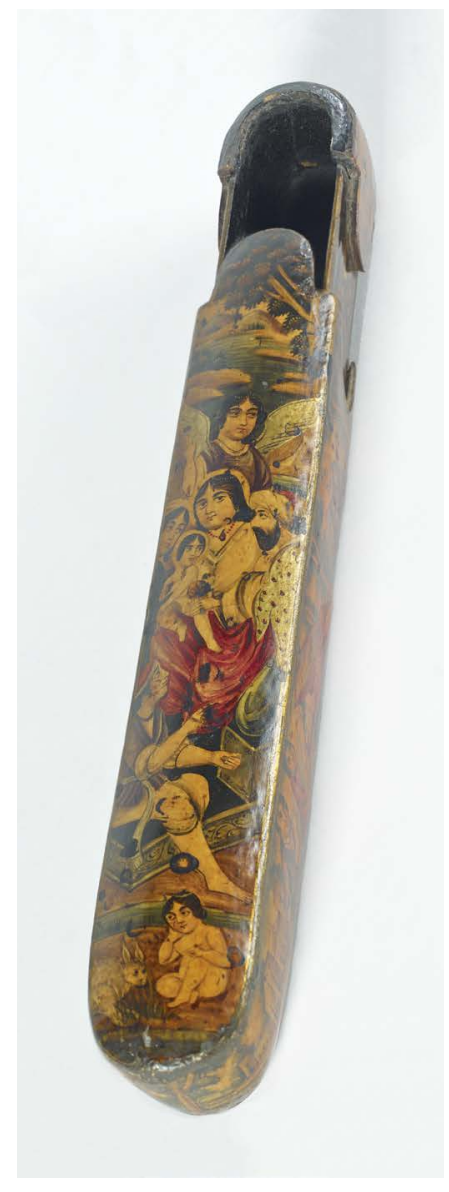

Ill. 2: Penneaske, MS OS 4.

Qajar, midten af 1800-tallet.

Top af beholder: Scene med dronningen af Sheba med et spædbarn og kong Solomon siddende omgivet af engle, hoffolk med fugle flyvende øverst og djævle og dyr nederst.

Sidestykke 1: Knælende munk foran en hvilende kvinde med to kvinder knælende bag hende i et landskab med europæiske bygninger.

Sidestykke 2: Siddende kvinde og en knælende kvinde i landskab foran en anden siddende og bagudlænende kvinde med en lille siddende kvinde bagved. Europæiske bygninger $\mathrm{i}$ baggrunden og på begge sideender.

Bundstykke: Bladranke med 15 bladcirkler bestående af omkredsende blomster i guld på sort baggrund.

Skuffesider: Blad i stjerne form og blomster ranke i guld på sort bagrund.

Indre og bund: Sort

Mål: Beholder: $22 \times 3,5 \times 3,8 \mathrm{~cm}$; skuffe: $21,7 \times 3 \times 2,7 \mathrm{~cm}$.

De håndværkere, der udførte ornamenterne med arabisk skrift, kunne som regel ikke læse eller skrive. Derfor så de skriften som et ornament ikke som en inskription, og hvis de ikke havde fået udleveret skriftligt forlæg kunne de selv sammensætte skriftstykker uden kendskab til betydningen, bare det så smukt ud.

Metalpenalhuse med udvendige tuschbeholdere blev undertiden mere enkelt dekoreret. ofte kun med ornamenter langs kanterne både på huset og tuschbeholderen. Disse ornamenter var for det meste lagt ovenpå metallet så de fremstod som ophøjede relieffer. Størsteparten af de nye enkle penalhuse kom fra det osmanniske område, mens penalhuse dækket helt af ornamenter var populære i Iran. Nogle af metalpenalhusene bærer inskriptioner, der oplyser om fremstillingsstedet og håndværkerens navn. En del har ligeledes en datering. Dog er Orientalsk Samlingens eksemplar uden inskription og datering, men dens ornamentering tyder på en fremstilling engang i 1800-tallet i Iran. 


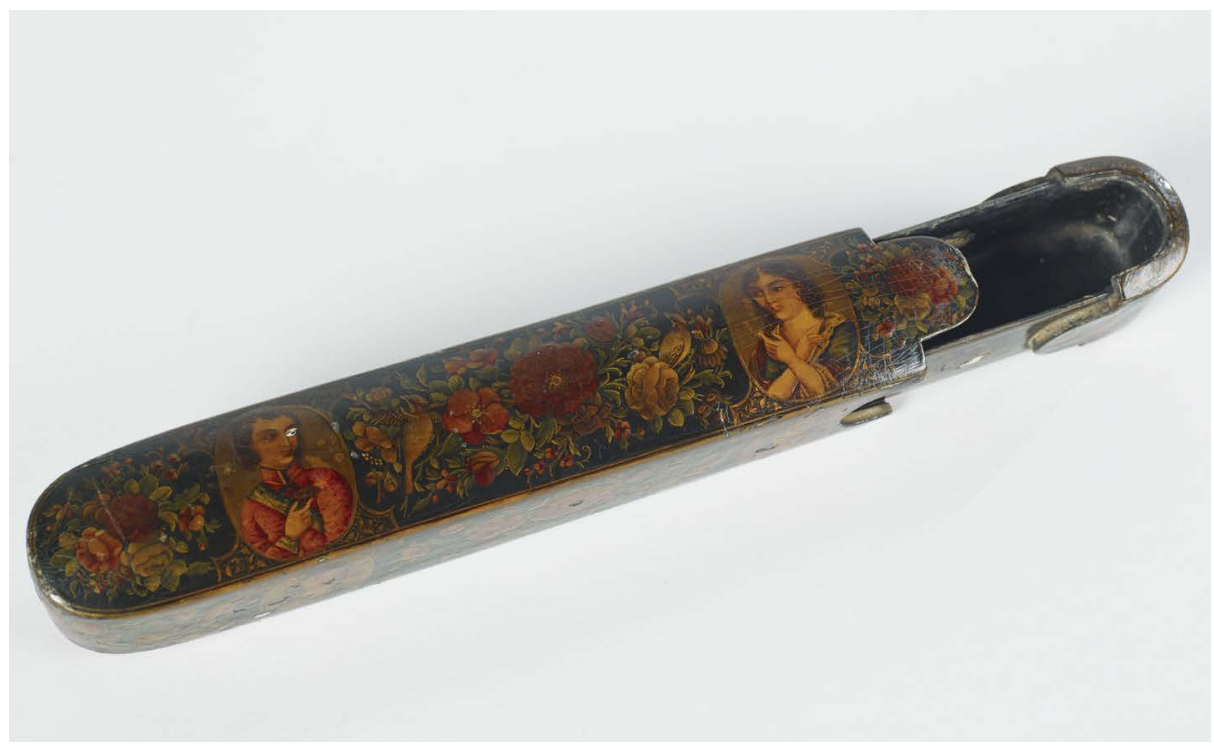

Ill. 3: Penneaske, MS OS 11. Qajar, midten af 1800-tallet.

Top af beholder: To portrætmedaljoner af en ung mand og en ung kvinder blandt to bulbul-fugle mellem blomster i fuld flor og blomstrende roser yderst. Bladranker i guld ved portrætmedaljonerne og skuffehåndtaget.

Sidestykker: På begge sider samme slags opdeling som på top, dog kun med kvinder i medaljonerne og med et forøget antal fugle blandt blomsterne.

Bundstykke: Rød med blad- og blomsterranke i guld.

Skuffesider: Sort med blad- og blomsterranke i guld.

Indre og bund: Sort.

Mål: Beholder: $22 \times 3,8 \times 3,8 \mathrm{~cm}$; skuffe: $22,3 \times 2,8 \times 2,8 \mathrm{~cm}$.

$\mathrm{D}$ e fire pennexsker i samlingen er alle fremstilet i papmaché. Der var to hovedfremstillingstyper af disse æsker. Den ene af dem bestod i at lægge lag på lag af papir og klister gradvist oven på hinanden henover en modelform. Den anden metode bestod af flere papirlag, der var klistret sammen før, de blev presset ind i en formmodel, hvorved æskens form fremstod. Oprindelig havde æskerne flade endestykker, men i begyn- delsen af 1600-tallet blev det mere almindeligt af have afrundede endestykker. Især de tidlige æsker med flade endestykker havde et toplåg med hængsler, mens æsker med afrundede endestykker bestod af to dele, hvoraf den ene lidt mindre del (skuffe) kan skubbes ind i den anden del (ydre beholder). Skuffen havde i den ene ende en forstærkning med en tunge på hver side som passede nøjagtigt ind i en fordybning på beholderen, så æsken kunne lukkes helt 


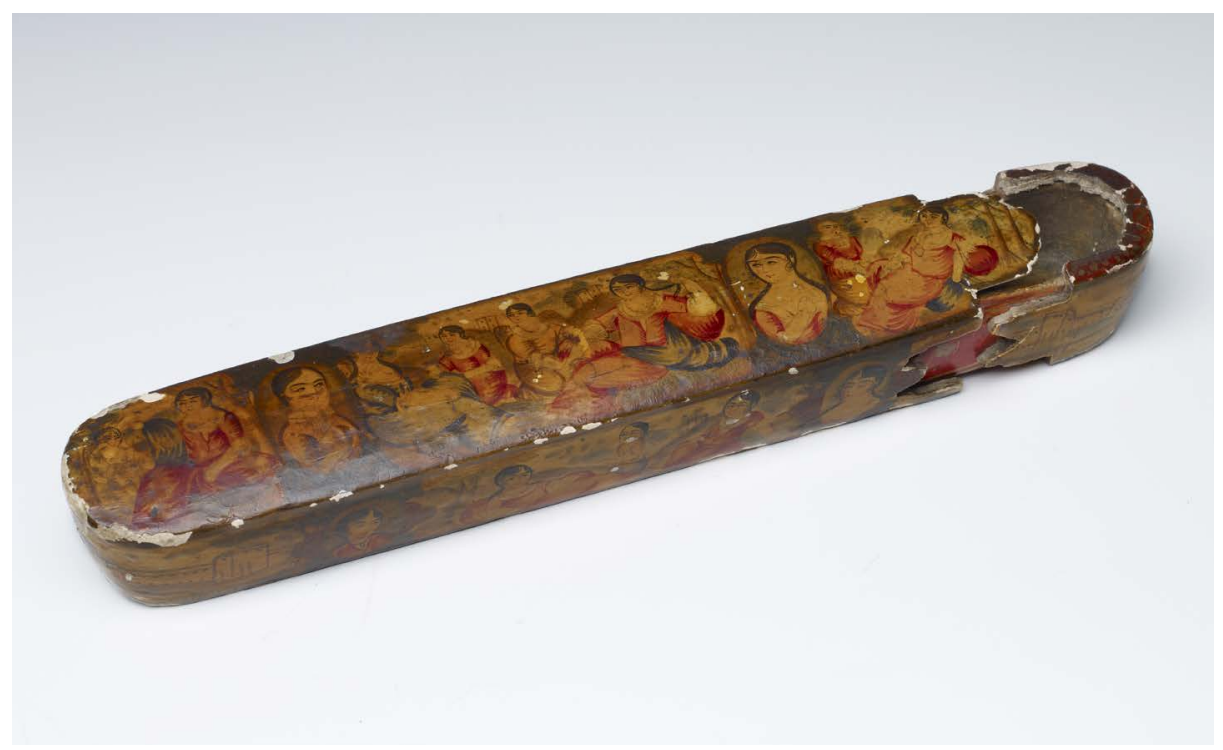

Ill. 4: Penneaske, MS OS 8. Qajar, midten af 1800-tallet.

Top af beholder: Pastoral scene med otte siddende kvinder mellem to indskudte portrætmedaljoner af en europæisk mand og kvinde.

Sidestykker: To siddende kvinder med en knælende pige mellem dem i landskab. Scenen flankeret af to portrætmedaljoner af to europæiske kvinder. Begge endeflader viser europæiske borge.

Bundstykke: Rød med bladranke i guld, der danner ni cirkler omkring diverse blomster.

Skuffesider: Rød med diverse blomsterranker i guld.

Skuffeindre: Malet i guld farve dog nu falmet

Skuffebund: Rød

Noter: Afslag på kanter, der viser den hvide gipsgrund.

Mål: Beholder: $23,2 \times 4 \times 3,5 \mathrm{~cm}$; skuffe: $22,8 \times 2,8 \times 3 \mathrm{~cm}$.

tæt. Tungestykkerne var enten udformet i en afrundet form, som en mennesketunge, eller formet $i$ et mønster, der enten kunne ligne et blomsterblad eller en slangelignende tunge ofte kaldt en dragetunge. Topstykket på beholderen er let opadbuet, mens bunden og siderne er flade (se ill. 2).

$\mathrm{P}$

enneæskerne af papmaché var almindeligvis dekorerede med billeder, blomster- og fuglemotiver og geometriske mønstre. Dekorationerne var malet med vandfarver på en gipsbund og blev beskyttet af en lakering. Lakken blev fremstillet af harpiks fra sandaractræet (Tetraclinis articulata) blandet med sesamolie eller valnøddeolie. Lakken beskyttede ikke alene dekorationerne men fremhævede dem også, så farverne og formerne stod meget klart frem. En del af æskerne indeholdt inskriptioner som kunne inkludere navnet på den kunstner, 


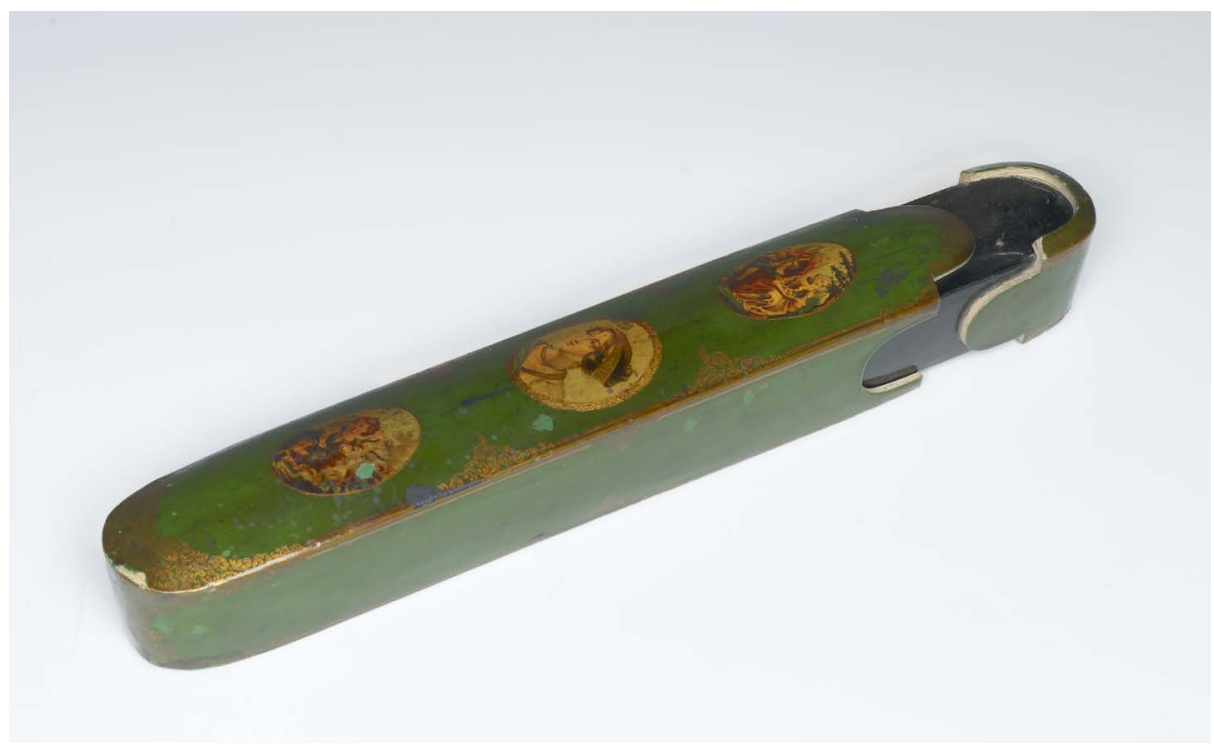

Ill. 5: Penneaske, MS OS 7. Qajar, sidst i 1800-tallet.

Top af beholder: Tre medaljoner (kartuocher) på grøn baggrund med et par i rokokoklæder, en buste af ung kvinde og en pige siddende ved siden af en gedebuk. Kanter malet med guldlinjer ornamenteret i seks spiralmønstre.

Sidestykker: Grønne og kun med guldlinjer og enkelte spiralmønstre i guld.

Bundstykke: Sort med dobbelt guldkant og fire enkle spiralmønstre i guld.

Skuffesider: Sort

Indre og bund: Sort.

Noter: Enkelte afslag, der viser en grøn gipsbund.

Mål: Beholder: $22,6 \times 3,6 \times 3,4 \mathrm{~cm}$; skuffe: $22,3 \times 2,8 \times 3 \mathrm{~cm}$.

der havde malet motiverne. Nogle af dem havde også en datering og ud fra disse kan det udledes at de lakkerede æsker dukkede op i Iran i begyndelsen af 1600-tallet.

Ideen til at male dekorationer på pennexsker afsluttet med et lag klar lak kom fra lakkerede bogbind, der formodentlig blev fremstillet fra slutningen af 1400-tallet. En del andre genstande blev ligeledes dekoreret med malede motiver og afsluttet med et beskyttende lag lak såsom spejlæsker, bogæsker, spillekort, mindre æsker, brilleetui og lignende. Det ser også ud til at malede dekorationer på disse genstande begyndte tidligt i 1600-tallet.

På penneæskerne placerede man først motiverne horisontalt på topstykket, men senere blev det mere almindeligt at anvende en vertikal orientering. Den horisontale placering var særlig anvendelig på motiver, der indeholdt mange dele og personer. Den franske greve Julien de 
Rochechouart (1830-1879) besøgte Iran i midten af 1800-tallet og beskrev dekorationsteknikkerne i en rejsebeskrivelse fra 1867 (se Rochechouart).

Motivkredsen for pennexskerne var ganske stor og den bestod dels af iranske og indiske traditionelle motiver og dels vestlige motiver. De vestlige motiver stammede fra grafiske blade, illustrerede bøger, malerier og lign. De iranske kunstnere greb ivrigt de vestlige motiver, men da en del af dem stammede fra billige og til dels pornografiske romaner var der mange europæere på besøg i Iran, der på den baggrund anså de dekorerede pennexsker som dekadente og uden kunstnerisk værdi. Blandt de traditionelle motiver fra Iran og Indien var historiske slagscener, banketscener, legender, romantiske fortællinger, portrætter af fyrster og fornemme kvinde og fugle- og blomstermotiver, hvor nogle af fuglene er forskellige sangfugle (bulbul-fugle). Fra Vesten kunne det være slagscener fra Napoleonkrigene, landskabsbilleder, bygninger, bibelske scener, portrætter af kvinder og mænd. Mange af de vestlige motiver kom fra russiske kilder, da Iran havde meget gode politiske og handelsmæssige forbindelser med Rusland. Elementer fra begge motivkredse kunne blandes såsom portrætter af vestlige personer placeret blandt de traditionelle iranske fugle- og blomstermotiver. Portrætter var som oftest anbragt i en form for kartouche med mere eller mindre ornamenterede rammer (se ill. 3); håndværkerne producerede deres egne motivbøger på baggrund af diverse forlæg, så de kunne hente inspiration til motiverne (se Roxburgh).

Penneæskerne fik som regel top- og sidestykker dekoreret, men undertiden kunne også bunden være dekoreret, samt skuffens ydre sider. Særligt fine æsker havde ligeledes malede udsmykninger på skuffens bunden og de indre sider. Nogle af siderne og bundene fik endda malede guldornamenter. De flader der ikke blev dekoreret havde en bundfarve dækket af lak, som beskyttelse.

De dekorerede lakerede penneæsker fra Iran blev produceret i store mængder og størstedelen af dem i det iranske Qajar-dynasti (1785-1925). Æskerne blev fremstillet i værksteder, hvor nogle af dem var ganske store. Mesteren for et værksted var ofte en fremragende kunstner og for at spare tid og øge produktionen malede han kun den vigtigste scene på topstykket, mens nogle af hans assistenter malede de øvrige sider. Da fotografiet kom til Iran i slutningen af 1800-tallet eksperimenterede penneæskeværkstederne med at overføre f.eks. portrætter fra fotografi til dekoration på en æske bl.a. via litografiteknikken. Selvom resultaterne var gode fik de ikke den store udbredelse. Da Qajar-dynastiet blev afløst af Reza Shah Pahlavi i 1925 (regererede 1925-1941) stoppede fremstillingen af alle typer af lakæsker hurtigt, da traditionelle produkter blev anset som umoderne.

Com det kan ses på de fire pennexsker stammede motiverne mest fra $\checkmark$ den vestlige verden: portrætter af europæer i vestlige klæder, landskabsscener, vestlige bygningsværker og en bibelsk scene, der alle tydelig stammer fra vesten. Det traditionelle iranske maleri indeholdt ikke landskabsscener i vestlig forstand. Miniaturemaleriet i Mellemøsten kunne inkludere landskab i deres motiver, hvor mennesker og dyr var de bærende emner, mens landskabselementerne kun var kulisser til en historie. Kvindemotivet, hvor 
den centrale figur læner sig tilbage (sidestykker på ill. 2 og front på ill. 4) kan være en sammensmeltning af det vestlige motiv med kvinder i naturen og indiske motiver med kvinder, der læner sig op ad en pude. De vestlige kvinder synes at sidde på jorden mens de indiske kvinder enten sidder på et tæppe eller en lav platform inde $i$ en bygning eller ude i naturen, som det kan ses $i$ en del indiske miniaturemalerier (kvinderne er ofte en Nayika, en af otte romantiske heltinder i indisk litteratur, se ill. 6). En af pennexskerne (ill. 3) har europæiske portrætmedaljoner omgivet af traditionelle iranske blomster og fugle. Lignende blomster- og fuglemotiver kan ses på spejlæsker og bogbind. Dette er et tydeligt eksempel på at malerne valgte motiver og ornamenter som de syntes understøttede hinanden uden at de kendte til udgangspunktet for dem. Blandt de fire penneæsker har æsken med dronning af Sheba og kong Solomon de fineste udførte motiver, især topdekorationen er elegant afstemt mellem formerne på de enkelte dele og farvelægningen.

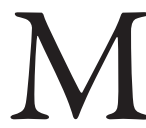
an kan spekulere på om motiverne på pennexskerne fra Qajar-dynastiet var bestemt for specielle købere som f.eks. indiske scener til indisk publikum, iranske scener til det hjemmelige marked og vestlige inspireret illustrationer til vestlige turister. Der er dog ikke noget der tydeligt peger hen på dette. Nogle af motiverne var bestilt af en køber, som derved bestemte motivvalget, men det var altid malerene der afgjorde udførelsen af dekorationerne. De fleste æsker var dekoreret af værkstederne uden at have en bestiller. Antallet af æsker med vestlige motiver er ligeledes så stort at turister og eksport til Vesten ikke har kunnet aftage dem alle. De vestlige motiver har ganske givet tiltalt et iransk og indisk publikum: det var nyt, anderledes og sikkert også et modefænomen.

\section{Litteratur:}

Folsach, Kjeld von: Kunst fra Islams Verden. København [Davids Samling], 2001.

Khalili, Nasser; Robinson, B.W. and Stanley, Tim: Lacquer of Islamic lands, part 1-2. Oxford University Press, 1997. (The Nasser D. Khalili collection of Islamic art vol. 22).

McWilliams, Mary (ed.): In harmony. The Norma Jean Calderwood Collection of Islamic art. London: Yale University Press, 2013.

Rochechouart, Julien de: Souvenier d'un Voyage en Perse, Paris: Challamel, 1867, Kapitel 23 "Du Cartonnage et de la Peinture."

Robinson, B.W.: Qajar lacquer i: Muqarnas, vol. 6 (1989), s. 131-146.

Roxburgh, David J... [et. Al]: An album of artists' drawings from Qajar Iran. London: Yale University Press (oct. 2017). 


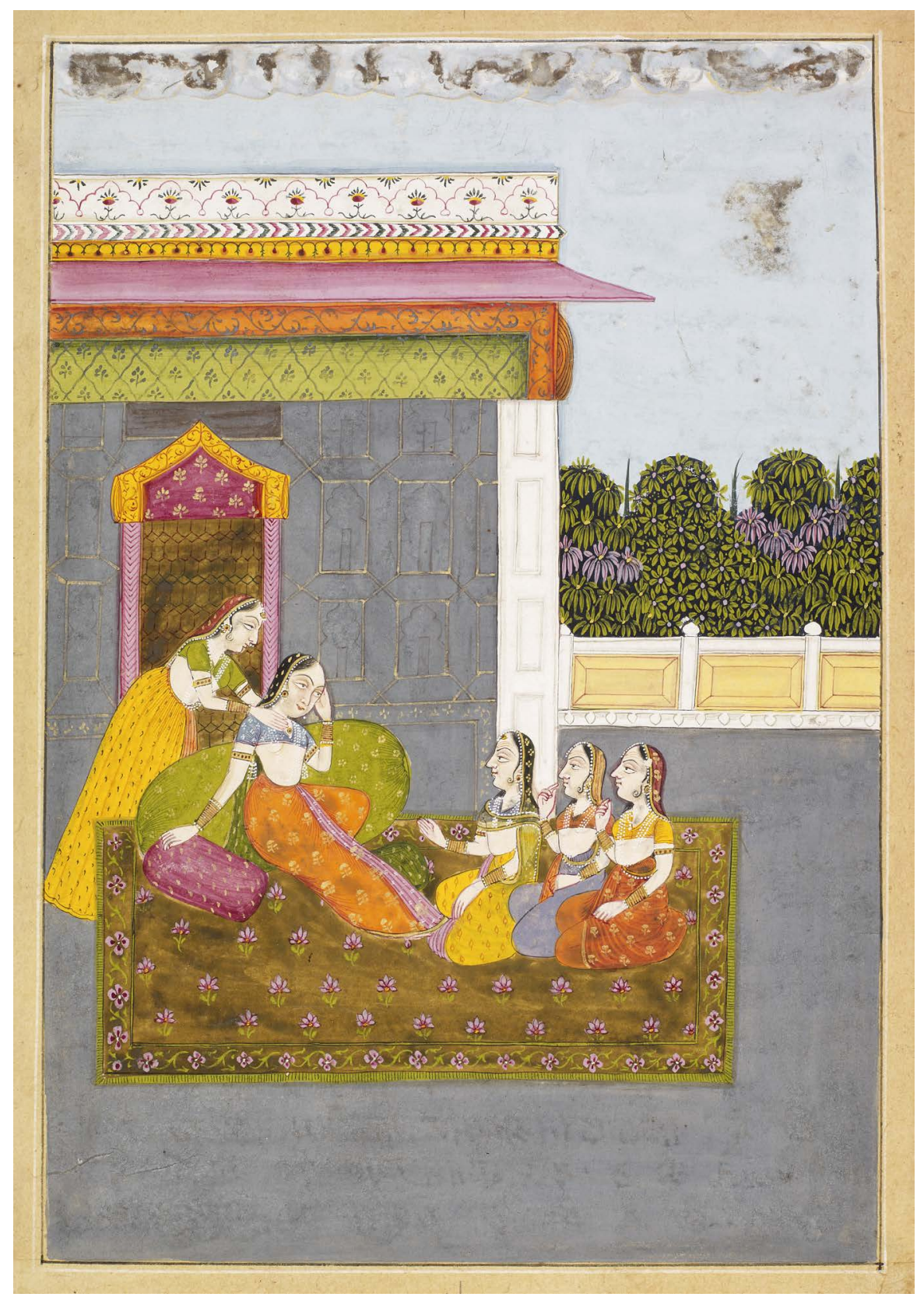

Ill. 6: En illustration af en af de otte heltinder i det indiske vark om scenekunst, Natya Shastra, af Bharata (levede mellem 100 fvt og $100 \mathrm{evt}$.). Denne miniature er fra byen Mandi i det nordlige Indien, ca. 1780-1790. $21 \times 14,5 \mathrm{~cm}$. (OS-1978-385)

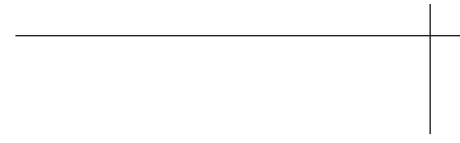

